\title{
Reward and threat in the adolescent brain: implications for leadership
}

Article

Accepted Version

Riddell, P. (2017) Reward and threat in the adolescent brain: implications for leadership. Leadership \& Organization Development Journal, 38 (4). pp. 530-548. ISSN 0143-7739 doi: https://doi.org/10.1108/LODJ-03-2015-0062 Available at https://centaur.reading.ac.uk/67655/

It is advisable to refer to the publisher's version if you intend to cite from the work. See Guidance on citing.

To link to this article DOI: http://dx.doi.org/10.1108/LODJ-03-2015-0062

Publisher: Emerald

All outputs in CentAUR are protected by Intellectual Property Rights law, including copyright law. Copyright and IPR is retained by the creators or other copyright holders. Terms and conditions for use of this material are defined in the End User Agreement.

\section{www.reading.ac.uk/centaur}

\section{CentAUR}

Central Archive at the University of Reading

Reading's research outputs online 


\section{Emerald Leadership \& Organization}

Reward and Threat in the Adolescent Brain: Implications for Leadership Development

\begin{tabular}{|r|l|}
\hline Journal: & Leadership \& Organization Development Journal \\
\hline Manuscript ID & LODJ-03-2015-0062.R3 \\
\hline Manuscript Type: & Research Paper \\
\hline Keywords: & Leadership development, adolescence, decision making \\
\hline \multicolumn{2}{|l}{} \\
\hline
\end{tabular}

SCHOLARONE ${ }^{\text {M }}$

Manuscripts 
Reward and Threat in the Developing Brain: Implications for Leadership Development

As adults, our decision making process involves a balance between taking and avoiding risk and thus involves assessments of both the rewards that might come from making the right choice and the threats to us if our choice is wrong. This involves a system of areas in the brain that includes (but is not limited to) the amygdala (threat detection and response), the ventral striatum (reward detection and response) and the prefrontal cortex (integration and regulation of emotions, planning and decision making). While the balance between these areas will differ between individuals, in general, adults are well equipped to integrate information about threat and reward, assess risks, and to use this to make decisions that fit the context - whether this is at home, at work or at play.

Statistics on, for instance, car crashes, binge drinking and contraceptive use indicate that adolescents and young adults take more risks (Steinberg, 2007). Indeed, the research suggests that their decision making processes are not fully developed until the early to mid-twenties. In order to explain this, researchers have studied the development of decision making in the brain and have found evidence that the balance between elements of the decision making system changes across the course of development with some parts of the system developing faster than others (Ernst, Pine \& Hardin, 2006). One hypothesis that this data has generated is that adolescents and young adults might be more sensitive to both reward and threat, and therefore are less able to regulate their responses than adults.

Potential developmental differences in the connectivity of the adolescent brain will have clear implications for how we might incorporate young adults into agile teams, and develop leadership skills in people of this age group. For instance, it is important to consider the role that experience of risk taking within a safe and structured environment has on the development of the connections between different parts of the decision making system. While age is a useful proxy for development, the way that our brains connect up is not simply driven by the length of time we have been alive. What is just as, if not more, important is the role of appropriate experience in strengthening decision making pathways. Thus, designing environments in which adolescents can be exposed to making the decisions required of leaders and experiencing the consequences of their choices could drive increased neural connectivity. Being a good leader benefits from leadership experience at any age, but is more important in adolescence since this will help to form the necessary neural systems that underpin leadership behaviour.

In this paper, I will discuss the developmental changes in connectivity that result in a reduction in risk taking with age, and will consider the implications of these changes for interventions to enhance decision making and leadership capabilities in young adults by providing a context in which the development of suitable neural systems is promoted. 


\section{Reward and Threat in the Adolescent Brain: Implications for Leadership Development}

Each decade, a new generation of workers enters the workplace with a label to define them. Generation $X$ are now between 40 and 50 years old, Generation $Y$ (or the Millenials) are between 22 and 39 years old, while Generation $Z$ are now 8 to 21 years old. Each time a new generation reaches the workplace, characteristics that define that generation are proposed, and then used to explain why this group might have different attitudes to work than previous groups before them. While historical changes in access to technology, internet use, the availability of free sources of, for instance, information and entertainment, and other similar factors are likely to change attitudes to work, it is possible that there are additional reasons for differences in attitude between older and younger workers. In this respect, we seem to have overlooked the commonalities in behaviour of younger people (of any generation) entering the workplace for the first time. The brain continues to develop into early adulthood and it is therefore important to consider the role that this might play in shaping differences in attitudes to work between younger and older employees. Developmental differences in the way that the brain processes information and makes decisions have important consequences for leaders managing each new generation of workers and also for the development of the leaders of the future. By addressing these differences, we can both motivate young people in the workplace better and enhance leadership skills within young adults. This is important since the Baby Boomer generation are coming close to retirement resulting in a shortage of skilled workers in Western Economies. In order to fill this imminent gap in leadership, we will need to develop more leaders. However, Generation X is smaller in size than the Baby Boomer generation that it succeeds (“Changing Global Demographics", 2011), and companies are implementing flatter organisational structures which require leadership skills at all levels (Schneider, 2002) and so younger employees will be required to fill this gap. For this to be successful, we need to be able to take account of immaturity in the brains of young people when implementing leadership development training.

Increasingly, this is also important for our concept of leadership more widely. Examples abound of individuals that have created companies in their teens and early twenties. Fred De Luca founded the Subway sandwich restaurant at 17 years old; Saba Ismail initiated "Aware Girls" (an organisation that aims to develop leadership capacity in young women) when she was 15 year old; Matt Mullenweg started Wordpress, the blogging software, at 19 years of age; and Mark Zuckerberg created Facebook at 19 years of age. It is therefore clear that there is much to be gained from encouraging leadership skills in the youngest members of the workforce. In addition, as more companies recognise the value in agile working practices, and the devolution of responsibility to smaller teams, individuals of all ages have the opportunity to develop leadership skills. Future leadership is likely to depend less on command-andcontrol and be more driven by context (Daimler, 2016). The rapid advances in technology that are influencing business practice are driving the need for cross-functional teams that bring together a range 
of skills and abilities (Daimler, 2016). A growing body of research into leadership views this as a collective action and advocates distribution of responsibilities across teams (McCauley \& van Velsor, 2004; Pearce, 2004; Miller, 1998). In this more collaborative, and less hierarchical structure, knowing how to make best use of the differences in thinking style in younger versus older employees has the potential both to create thriving communities and drive profit.

One of the major developmental changes that occurs between adolescence and late adulthood is in the neural systems that form the basis of decision making. Decision making is ubiquitous in our lives - we do this many hundreds of times per day. Some decisions are relatively trivial like what to have for breakfast, or what television programme to watch. Others have much greater magnitude; for instance, deciding what house to buy, what career to follow, or who to hire and fire.

Many of the most important decisions we make involve a degree of risk. For some of these decisions, the level of risk can be quantified, for instance, we can calculate the exact odds of winning the lottery. But sometimes we have to make decisions without being able to determine the likelihood of success and thus these decisions involve uncertainty and ambiguity. In these cases, we have to estimate the outcomes of possible decisions and then determine whether the potential gains outweigh the potential losses. This suggests that decision making involves a careful, conscious cost:benefit analysis of each decision (slow thinking), however it is clear from some introspection that this does not always happen and therefore that some form of unconscious decision making (fast thinking) must replace this (Kahneman, 2011). Consequently, there must be many parts of the brain, to which we have both conscious and/or unconscious access, that are involved in the decision making process.

The ability to make decisions, in both risky and non-risky situations, depends on neural systems that have adapted over millennia. This adaptive process will have retained neural solutions that produced improved survival in our environment. Thus, the type of decisions we were required to make prehistorically, and the contexts in which these decisions were made, will have partly driven the evolution of the decision making systems in the brain that we use today (Cosmides \& Tooby, 1996). For instance, the lack of complex systems to represent numerical quantities suggests that information might be stored in terms of observable frequencies. Thus, humans find it easier to interpret frequency information (1 out of a hundred patients taking this drug will develop unpleasant side effects) rather than probabilities (there is a 0.01 chance that an individual will develop unpleasant side effects from taking this drug). Having access to frequency information is important since it allows risk to be calculated and incorporated into decision making. Thus, understanding this evolutionary perspective has contributed the design of current models of adult decision making (Cosmides \& Tooby, 1996). 
In addition to the evolutionary perspective which has been important in our species-level understanding of the decision making process, there is also development at an individual level. Since human brains are immature at birth, a developmental process which takes place across the lifespan of the individual is also required to reach mature decision making. This developmental process will be dependent on the environment in which an individual is raised including the support they receive as children, their friends and peers, their educational environment and the opportunities and challenges that are presented during development. In this paper, the changes that occur in decision making processes during development and the role of individual experience in shaping decision making will be considered. This will be followed by reflection on what this implies about how to develop better leadership skills especially during the critical developmental period of adolescence and early adulthood.

\section{Decision making in the adult brain}

\section{Decision Making Processes}

Making a decision is a complex process which requires a number of component stages. First, it is necessary to represent the relative values and relative risks of each option so that, through comparison of the available options, the best option can be chosen. For a decision to drive behaviour, the chosen option has then to be associated with an action, and, has to produce the motivation necessary to perform that action. While most choices will lead to actions, it is also possible that the choice made will require inhibition of an old action rather than, or in addition to, production of a new action. Thus, decisions can both drive new behaviour and inhibit old behaviours.

Part of the benefits that are derived from decision making is in determining whether the outcome of a decision was beneficial or not. This allows our experience of past decisions to be used to predict both the decisions we can make and the behavioural choices that arise from these. For this to happen, the effect of the action that resulted from a particular decision has to be coded. Two measures are important: the valence of the outcome for a decision (did it have a good or bad effect) and the intensity of the outcome (how good or bad was it). These measures provide a means for individuals to learn from the outcome of their decisions over time so that this learning can be used to improve future decision making. Finally, our socio-emotional state will influence the decisions that we make. Decisions, along with the likelihood of following through on any actions, can change depending on our mood, or our social environment; for instance, whether we are alone or in company, or whether the action would be approved by parents, friends or colleagues. 
It is clear from this description of the decision making process that it must involve many areas of the brain. From the input of information through our senses (vision, sound, touch etc.) to the action that is created as a result of the decision making process (motor systems) different parts of the brain are recruited in order for a decision to result in action. In order to simplify the neural representation of decision making, this discussion will centre on the Triadic model of the brain areas involved in decision making (Ernst, Pine \& Hardin, 2006). This model incorporates three main areas: the first is the reward system in which a representation of the degree of reward associated with a particular option is calculated and stored (ventral striatum/dopamine reward system). This system in the brain computes the likelihood that we will choose a particular option. When this part of the brain is active, we are more likely to approach new situations and to repeat rewarded behaviours. The second area of the brain that is essential for decision making is the system which indicates the degree of threat that is associated with a particular choice, and therefore represents the likelihood that we will not choose that option (amygdala). When this part of the brain is active, we are more likely to avoid a particular situation or to choose not to repeat a behaviour. Finally, the regulatory system (prefrontal cortex) is the part of the brain which takes the context of the situation into account. This part of the brain modulates the responses of the reward and threat systems through experience of cultural expectations for this type of decision, the social situation in which the decision is being taken and other contextual variables. The balance between these three areas indicates the degree to which a particular option is valued (balance between approach and avoid) within a particular context.

To give an example of how these three areas might operate together, consider the following scenario. At the start of the day, deciding whether to drink coffee might activate the approach system more than avoidance system as we recall the reward of the stimulating properties of caffeine. This might drive us to make a cup of coffee (decision to take action). However, at the end of the day, these same stimulating properties might result in a decision to avoid coffee (decision not to take action). The context for the decision (the time of day) is important in decision making and it is the regulatory system that takes information of this type into account and therefore modifies the degree to which we consider a particular outcome rewarding (coffee in the morning) or threatening (coffee at night). Thus it is not just the level of activation of individual components but their interaction that is important in decision making. Imbalance in one component can alter the decision made.

\section{Fast and slow thinking in decision making}

In addition to considering the different component processes in decision making, researchers also differentiate between the unconscious, fast, parallel decision making system (system 1 ) and the 
conscious, controlled, slow decision making system (system 2) (Evans, 2003). These dual decision making processes are respectively associated with emotional and incentive driven decision making which is intuitive (system 1), and the more cognitive inhibitory system which involves more conscious cost benefit analyses (system 2).

It is clear that adults do not rely exclusively on system 2 thinking since Tversky and Kahneman (1974) have demonstrated many ways in which biases and heuristics (cognitive short cuts) affect decision making. For example, research has shown that a change in the framing of a problem can cause a different decision to be made from exactly the same data (Tversky \& Kahneman, 1986). So, for instance, in the dread disease paradigm, participants are told that 600 people are expected to die from a new disease. They are then asked to choose between two programmes that can be implemented to combat the disease. In the first programme, there is a certainty that 200 people will be saved, while in the second programme, there is 1:3 probability that 600 people will be saved and a $2: 3$ probability that no one will be saved. In this case, the majority of participants choose the first programme in which there is a certainty that some people will be saved over the second programme where there is a chance that no one will be saved. However, the problem can be framed differently. In an alternative scenario, participants are told that the first programme will result in 400 people dying (which is numerically equal to 200 people being saved) while in the second programme, there is a 1:3 probability that nobody will die and a 2:3 probability that 600 people will die. In this condition, more people choose the second programme since it is possible that nobody will die. Thus, although the choices are identical, the frame can change the decision made. If decision making in adults was exclusively dependent on system 2 , the actual lives saved would be calculated accurately in each case and so the frame would not affect the final decision.

In an attempt to explain these findings, Reyna \& Brainerd (1991) suggest that system 1 thinking involves extracting information from memory that is not coded in detail but is represented as gist. Thus, instead of retrieving the detail when making a decision, the gist of a previous experience is retrieved. In comparison, Reyna and Brainerd suggest that system 2 uses information that is present in the moment in detail to compute an exact verbatim form of the problem space. It might be thought that adults would be better than children and adolescents at decision making because they are better able to use system 2 thinking, but the results of the studies by Tversky and Kahneman (1974) suggest that adults often use gist (system 1) rather than verbatim (system 2) representations when making decisions. Experience of similar problems in the past is generalised and the gist of these experiences is stored as system 1 representations resulting in increased expertise. Thus, adult decision making often depends on information stored in system 1 or gist based decision making but benefits from a more accurate use of expertise which might have been calculated initially on the basis of verbatim representations (system 2). 
How is decision making different in adolescence and young adulthood?

Adolescence is defined as the time between the start of puberty and ends as individuals become stable members of society (Steinberg, 2010). During adolescence and early adulthood, decision making processes appear to operate differently in comparison to mature adults. Anecdotally, adolescents are noted for their lack of self-control and foresight (Steinberg, 2008). This period of development is accompanied by substantial changes in cognitive abilities, emotionality, self-concept, and social functioning including a movement away from dependence on parents to monitor behaviour, and a greater reliance on peer support. During this period, adolescents appear to take more risks. They are more likely to participate in dangerous driving, drug and alcohol abuse, and unprotected sex (Viner, Ozer, Denny, Marmot, Resnick, Fatsui \& Currie, 2012). It is therefore important to determine the changes in neural processing that underlie these differences in decision making, both to protect adolescents during this vulnerable time, and to capture the best aspects of their decision making processes in order to help them develop to their full potential.

\section{Brain development}

The brain develops progressively from birth with changes continuing into early to mid-twenties. Different areas of the brain develop at different rates, and this can have an effect on the balance within systems in the brain. Importantly for decision making, there are differences in the rate of development of the components of the triadic brain. The ventral striatum which underlies the approach system appears to develop rapidly and substantially during early adolescence, with slower development towards the end of adolescence (Ernst \& Spear, 2009). The effect of this is that sensitivity to reward peaks early in adolescence. Similarly, the amygdala which underpins both the aversion system, and is involved in the representation of both positive and negative emotions, also develops relatively faster during early compared to late adolescence. This correlates with increases in emotional instability and intensity which are highest during early adolescence (Arnett, 1999; Weinstein, Mermelstein, Hankin, Hedeker \& Flay, 2007). Regulation of the amygdala and ventral striatum depends on the development of the prefrontal cortex which is responsible for top down control of these structures (Amodio \& Frith, 2006; Aron, Robbins \& Poldrack, 2004; Chikazoe Konishi, Asari, Jimura, Miyashita, 2007; Rubia, Hyde, Halari, Giampietro \& Smith, 2010). Unlike the subcortical structures (ventral striatum and amygdala), the cortical structures involved in top-down control appear to mature linearly with age and so have a longer developmental time course lasting into the late adolescent, early adult phase (Marsh, Zhu, Schultz, Quackenbush, Royal, et al., 2006; Rubia, Smith, Taylor \& Brammer, 2007). 
The differences in maturational time course across areas of the brain results in earlier development of sensitivity to reward and emotional processes than the regulation of these processes. In particular, adolescents and young adults are less able to regulate decision making when in heightened positive or negative emotional states (Cohen et al., 2016). Thus the decision making processes continue to develop throughout childhood, adolescence and into early adulthood with full adult like decision making finally in place until after 21 years of age (Cohen et al., 2016). While decision making in children is relatively underdeveloped, this is mitigated by the fact that children are still aided in their decision making by their parents. During adolescence and young adulthood, however, as the drive for independence increases, the role of parents diminishes and therefore the consequences of immaturities in decision making processes are greater during this stage in development.

\section{Developmental differences in decision making processes}

What are the consequences of the faster development of sensitivity to reward and threat and greater emotional lability along with slow development of cortical control and regulation of decision making in adolescence and early adulthood? There is considerable research addressing the development of aspects of decision making in adolescents. In most cases, the research has compared groups of children, adolescents and older adults. Thus, it is only possible to discuss deficits in decision making in adolescents but, in most cases, we do not have research to determine exactly the age at which each process is fully mature. Where this information is available, it has been reported.

Development of Inhibition

One factor that is important in decision making, and that is thought to develop during this time, is the ability to inhibit responses (Blakemore \& Robbins, 2012). Studies that investigate inhibitory processes make use of tasks in which frequent stimuli that are associated with making a response (go stimuli) are interleaved with occasional stimuli that require no response (no-go stimuli). Thus participants might be asked to respond with a button press if they see a consonant (frequent stimulus) but not to respond when they see a vowel (infrequent stimulus). Ability to inhibit a response is then assessed by calculating the proportion of no-go stimuli that activate a go response, as a proportion of the total number of incorrect responses. Poor inhibition is indicated when this proportion is large since it suggests that most errors result from failure to inhibit the response to the no-go stimulus. Results from this task suggest that there is protracted development of the inhibition process with children performing more poorly than adolescents who in turn perform more poorly than adults (Luna, Padmanabhan \& O'Hearn, 2010). The development of inhibition has been shown to be dependent on the continuing development of the dorsolateral prefrontal cortex - an area of the brain involved in cognitive control. Activation in this area 
in adolescents for a relatively simple task is similar to the activation in adult brains when performing a more complex task suggesting that adolescents have to work harder at inhibition. Further, gender differences in this ability have been identified with females outperforming males during adolescence (Campbell \& Muncer, 2009; Rubia, Lim, Ecker, Halari, Giampietro, Simmons et al., 2013). This difference is no longer present by the mid-twenties (Rubia et al., 2013).

\section{Development of Reward}

In addition to inhibitory processes, the degree to which adolescents are more sensitive to reward has also been studied. The findings here are mixed with research suggesting that, while children and adolescents show greater activation of both the ventral striatal reward centres and the orbital prefrontal cortex to rewarding stimuli in comparison to adults, this was not associated with differences in performance in a reward related task when compared with adult performance (Galvan, Hare, Parra, Penn, Voss, Glover \& Casey, 2006). This would suggest that, similar to the pattern found for inhibitory responses, adolescents have to work harder (greater brain activation) to perform at the same level as adults on reward tasks. However, in a go no-go task in which the go trials were associated with non-rewarding neutral faces while the no-go trials were associated with happy faces, adolescents demonstrated poorer inhibitory control and this was associated with greater activity in the ventral striatum (Somerville, Hare \& Casey, 2014). Increased reward-related activity was not found in either children or adults suggesting that increased reward sensitivity, at least to social stimuli, is especially present in adolescents.

\section{Development of Risk}

Just as adolescents have been shown to be particularly sensitive to reward, they also show increased sensitivity to risk. Dreyfuss, et al. (2014) repeated the go-no go task used by Somerville et al. (2014) but replaced the happy faces with angry faces. Thus, participants were asked to respond with a button press when they saw a neutral face (go stimulus) but to inhibit the response when they saw an angry face (nogo stimulus). This tested the ability to inhibit a response to a threatening situation. Results demonstrated that, just as adolescents failed to inhibit their response to rewarding social stimuli, they were also less able to inhibit their response to a threatening social stimulus than either children or adults. However, in this case, the effect was significant for adolescent male participants only. Female participants were equally able to inhibit their response to angry faces at each age tested.

In a similar study, van Leijenhorst, Moor, Op de Macks, Rombouts, Westenberg, \& Crone (2010) separated out the effects of risk and reward. In their study, participants chose whether to gamble on a low risk, low 
reward option or a higher risk, higher reward option. The showed that, at all ages tested, participants became more likely to choose the higher risk option as the reward increased. However, there was an agerelated decrease in the number of higher risk options that were chosen when the reward was low. This suggests that older participants were more sensitive to the negative aspects of risk taking than younger participants. This increased sensitivity to risk was associated with a linear decrease in activation within the dorsal anterior cingulate cortex, a part of the brain associated with error detection and cognitive control. Thus, older adults were able to determine the relative benefit of a small increase in reward when it also involved greater risk and inhibited their response to the slightly higher reward option in order to choose the lower risk, lower reward option. However, the subcallosal cortex, an area associated with response to risk, was more highly activated in the adolescent group than in either children or adults suggesting that adolescents have a stronger response to risk. This study did not look at gender and so it is not possible to say whether this effect was driven more by males than females. In summary, these studies suggest that adolescents are more likely to approach both rewarding and threatening risky situations than either children or adults and that this effect might be greater in males than in females.

\section{Effects of Context}

The studies described above suggest that adolescents are more sensitive to reward, but also more likely to take risks both for monetary gain and in social situations. There is a possibility, therefore, that contexts in which social reward is manipulated by the presence of peers might create greater sensitivity to reward and less sensitivity to risk. This was tested by Albert, Chein and Steinberg (2013) using a driving simulator in which participants were asked to reach the end of a track as quickly as they could. Performance was assessed on the number of risky decisions taken (indicated by driving too fast and/or braking too late) in two conditions: when driving alone and when driving in the presence of peers. Adolescents made significantly more risky decisions than either young adults or older adults when in the presence of peers and this correlated with greater activation in the ventral striatum (reward system).

This study was repeated by Silva, Chein and Steinberg (2016) with slightly different conditions. Risky driving behaviours in a group of adolescents were assessed when driving alone, with 4 same-age peers present or with 3 same-age peers and an older adult (mean age 25 years of age) present. This study replicated the finding of greater risk taking with peers only present but also showed that risk was reduced to the same level as when driving alone in the presence of the older adult. Thus, social context effects can be manipulated by including people from different age groups. 
$\underline{\text { Temporal Discounting }}$

Another area of decision making that has been studied in adolescence is temporal discounting. One of the ways in which the irrationality of the adult decision making process can be demonstrated is by determining the degree to which a reward has to be greater in the future to match an immediate reward (Loughran, Paternoster \& Weiss, 2012). By definition, current and future rewards are matched when they are equally likely to be chosen. To do this, adults are given the value of an immediate reward, and are asked if they would choose to give this up for the same or a larger reward at a later point in time. By varying the delay before receiving, and the value of, the later reward, we can measure the degree by which later rewards are devalued or discounted. Typically, in order to match immediate reward, the later reward has to be made progressively larger as the delay before receiving this reward increases. The steepness of this function (the increase in reward over increasing delay) provides an index of the degree to which future rewards are discounted with respect to immediate rewards (temporal discounting). The steeper this function, the less tolerant of delay an individual is. Temporal discounting has been demonstrated to correlate with other measures of self-control (Rachlin \& Green, 1972).

Temporal discounting has been compared in adolescents and adults (Christakou, 2014; Christakou, Brammer \& Rubia, 2011). These studies have shown that adolescents have steeper temporal discounting than adults (are less tolerant of delay). Neural imaging during this process suggests that steepness of temporal discounting is positively related to the degree of activation in the ventral striatum (immediate reward) and is negatively related to activity in the prefrontal cortex (cognitive control). Indeed, improvements in temporal discounting that occur with age appear to involve increased connectivity between the ventromedial prefrontal cortex and the ventral striatum (Christakou et al. 2011). Since adolescents are less tolerant of delay in reward than adults, their behaviour is more likely to be driven by immediate reward than reward in the future.

\section{Prediction Errors}

In order to learn from experience, the value of different decisions has to be stored and compared so that the best solution can be made when a similar situation is met in the future. Thus, decision making in adolescents might be poor if they are good at establishing the reward value of a single decision but less competent at updating this information over time with each new decision (Cohen, Asarnow, Sabb, Bilder, Bookheimer, Knowlton et al., 2010). In order to update the outcome of decisions, an expectation about the reward (or punishment) associated with each decision has to be calculated and compared to the actual reward (or punishment) received. This creates a measure of the difference between the predicted reward and the actual reward. If these are different, then there is a prediction error. Thus, when the 
reward received is greater than the reward expected (or the punishment received is less that the punishment expected), there is a positive prediction error - the outcome is better than expected. Negative prediction errors occur when the reward received is less than the expected reward (or punishment received is greater than the punishment expected) and thus the outcome is worse than expected. If adults are better than adolescents in their ability to accurately predict expected rewards and punishments, they will make more accurate predictions about the effects of their decisions.

Research has assessed the ability of adolescents and adults to use negative and positive prediction errors. Results suggest that adolescents weight negative and positive errors equally, while adults put greater weight on negative prediction errors (Christakou, Brammer, Giampietro \& Rubia, 2009). This suggests that adults learn more from negative experiences than adolescents who might therefore be expected to be more optimistic about the result of a risky decision. Again, this change in behaviour has been related to improved connectivity between areas of the prefrontal cortex and the ventral striatal reward areas (Christakou et al., 2009).

Studies investigating the use of prediction errors in social situations suggest that differences between adolescents and adults are enhanced when the source of feedback is social. Research has demonstrated that adolescents have heightened self-consciousness which is related to higher activity in medial prefrontal cortex, an area of the brain known to be involved in self representation (Sebastian, Burnett, \& Blakemore, 2008). In one recent study, adolescents were tested on their ability to learn in a decision making task when the feedback was in the form of positive or negative social feedback (Jones, Somerville, Li, Ruberry, Powers, Mehta et al., 2014). As with other sources of feedback, prediction errors for social feedback were found to be represented in the prefrontal cortex and ventral striatum. When adolescents were compared to children and adults, however, it was found that the adolescents did not change their response depending on the size of the social reward but were equally sensitive to small and large rewards. This was in comparison to both adults and children who scaled their responses dependent on the size of reward. This suggests that adolescents are more responsive to any peer feedback than adults or children.

\section{System 1 and System 2 thinking in adolescence and young adulthood}

One way in which the reported differences in adolescent and adult neural function can be characterised is to suggest that the difference in maturational time course of different brain areas in adolescents results in adolescents being impulsive and more likely to make risky decisions especially when they are in emotional situations and/or with their peers. However, this would imply that the differences in decision making ability are only disadvantageous to adolescents and would miss any benefit that might result from this 
developmental time course. What might be more helpful therefore would be to consider models of cognition and to determine how these changes relate to ways in which we learn from experience.

Making decisions based on immediate calculation of emotional and social reward can be characterised as system 1 thinking, while learning by updating expected outcomes based on prediction errors and using these to inhibit possibly risky decisions can be characterised as system 2 thinking. In this case, it would suggest that adolescents are more prone to use system 1 than system 2 thinking. However, this does not take the effect of context into account. Much of our adult decision making depends on estimating missing information based on experience, and then incorporating our estimations into our heuristics and biases (Tversky \& Kahneman, 1974). This allows us to make rapid decisions based on our past experience without having to compute all of the pros and cons each time. This is an elegant evolutionary solution to the complexity and time-consuming nature of decision making (Cosmides \& Tooby, 1996).

Since the development of heuristics and biases depends on experience, they inevitably will continue to develop throughout childhood and into adolescence as new experiences are encountered (Reyna, 2012). This would suggest that children and adolescents are unable to generate good estimations of missing data for system 1 thinking and therefore are more dependent on verbatim representations of the world (system 2 thinking) than adults who have extracted gist through experience. This provides an alternative explanation of the risky decision making of adolescents. It suggests that adolescent decisions made on the basis of a verbatim calculation of the pros and cons are as accurate as in adults. In contrast, since adolescents have little expertise from which to judge possible outcomes of decisions, system 1 thinking is less developed than in adults. For instance, if the benefits of a risky behaviour are high (e.g. peer approval) while the risks have not been experienced (getting drunk for the first time), then the risky decision is likely to be accepted. In comparison, adults can use gist thinking to point to a different gist interpretation that is based on experience of prediction errors (I thought I would enjoy drinking a lot but hangovers are horrible and I don't want to go through that again). Research suggests that this explanation of adolescent decision making is more accurate in predicting decisions than when considering reward sensitivity and inhibitory control alone (Reyna, Estrada, DeMarinis, Myers, Stanisz \& Mills, 2011). Indeed, this theory can also explain the difference between the decisions made by beginners and experts in their field of expertise, and correctly predicts greater bias in performance for experts of any age than for beginners (Reyna, Chick, Corbin \& Hsia, 2013).

In this description of adolescent decision making, it is not the decision that is faulty, but the experience on which the decision is made. Lack of experience results in poor prediction of possible outcomes and therefore decisions are based on correct interpretation of immediately available information. 


\section{Leadership Development during Adolescence}

In a recent review of leader and leadership development, Day, Fleenor, Atwater, Sturm and McKee (2014) discriminate between leader development with a focus on the development of individuals as leaders and leadership development which is a broader process involving multiple individuals (e.g. leader, role models, followers etc.). They note that the development of leaders takes place within the broader context of the biological and social development of the individual during emerging adulthood. For this reason, the developmental aspect is as important as the leadership aspect when considering how we create individual leaders. Adolescence and early adulthood is a period during which individual personality characteristics suitable for a leadership identity can be developed through experience. Hence, organisations have the opportunity to develop their future leaders by providing suitable experiences during this developmental period.

Developing leaders through experience with leadership has been shown to deliver improvement in a number of important skills (Hezlett, 2016; Yeager \& Callahan, 2016; Avolio \& Vogelgesang, 2011). Kraiger, Ford and Salas (1993) suggested that leadership skills could be divided into cognitive learning (including for instance organisation of knowledge and self-regulation), skill-based learning (including technical skills and interpersonal skills) and affective-based learning (including attitudinal change and motivational change). Further research has demonstrated that each type of skill can be built through specific leadership experiences within the organisation (McCall, Lombardo \& Morrison, 1988). Thus, selfregulation can be developed through persevering to achieve challenging goals; interpersonal skills can be developed through dealing with people from diverse backgrounds including older employees; attitudinal changes develop through increased self-awareness of the behaviours required of a leader and development of leadership values; and motivational change can develop through success in leadership positions which build self-esteem and self-confidence along with a leader's identity.

Building different skill sets will require different experiences within an organisation. In a series of interview studies, McCall, Lombardo and Morrison (1988) identified particular situations which are effective in the development of leadership skills. These included challenging assignments which provide practice and greater responsibility in situations in which change is required. Situations of this nature often necessitate working with people from a range of backgrounds across different sectors within an organisation. This requires interpersonal skills including being able to view the situation from a range of different perspectives in order to, for instance, address individual concerns with the change that is being implemented. Action learning, in which a small group work together on an important and/or urgent task has been shown to improve development of leadership skills (Leonard \& Marquardt, 2010) as has job rotation which particularly promotes adaptability and flexibility (Campion, Cheraskin \& Stevens, 1994). 
While it is possible to learn leadership skills in a workplace setting, some adolescents begin this process during school. For instance, Yeager and Callahan (2016) interviewed 5 males and 5 females aged from 1820 who had held a leadership position during high school to determine what experiences had been influential in developing leadership skills. The interview data was used to create a model explaining the development of a leadership identity including leadership authenticity (behaving as a leader) and motivation to lead. Two types of experience were found to be important in creating this identity relationships with authority figures, peers and members of their school; and both learning to lead through the example of other leaders and providing an example of leadership to others in the school. The importance of both relationships with authority figures and learning through watching the leadership behaviours of these figures suggests that structured mentorship might be an important factor in leadership development.

\section{Implications for leadership development}

Each of the areas of brain development considered can be used to provide suggestions for how to best guide leadership development in young employees. The implications and possible actions are listed in Table 1 and each is considered in more detail below.

--- Table 1 about here ---

$\underline{\text { Inhibition }}$

Research has shown that adolescents are less able to inhibit previously rewarded responses than older adults with inhibition reaching adult levels after 21 years of age. It also suggests that this effect is stronger in males than females. In order to counteract this, young employees can be encouraged to develop a leadership identity through opportunities to lead by example. Provide projects which require leadership of a diverse group and emphasise that success will depend on leading by example. These opportunities can be created through action learning where a small group comes together with a coach and commits to learning during the completion of an urgent task or project (Hezlett, 2016; Leonard \& Marquardt, 2010). By adding diversity to the group, opportunities for developing relationships with different people are created. In order to lead older and younger people, attributes of consistency, respect, accountability and fairness are essential (Yeager \& Callahan, 2016). These attributes require that the young leader inhibits their own need for reward, or their need to be part of a particular social group, in order to be fair to the whole group. Experiences of this type have the potential to increase the strength of connections between the prefrontal cortex and reward centres promoting greater ability to inhibit short term rewards. 
Behaviours that involve failure to inhibit previously rewarded responses are more prevalent in young men than young women and so this approach is likely to be more necessary for young males.

\section{$\underline{\text { Reward }}$}

Evidence suggests that adolescents are highly sensitive to reward. Positive and constructive feedback can be used to reward successfully completed leadership challenges through mentorship schemes (Yeager \& Callahan, 2016). Since adolescents and young adults are particularly sensitive to social reward, demonstrating appreciation of their contribution to tasks would act as a suitable reward especially if this appreciation is public and therefore communicated to peers. This provides reinforcement of leadership behaviours and can be used to support the creation of a leadership identity.

\section{$\underline{\text { Risk }}$}

In addition to increased sensitivity to reward, there is a decreased sensitivity to risk especially in males. Learning about leadership can be developed both through the reward of success and through reflecting on failures (Aviolio \& Vogelgesang, 2011). Providing opportunities to lead higher risk projects which have a low cost of failure has the potential to provide opportunities to celebrate success or to reflect on failure if the project does not come to fruition. Failure of a project can lead to a trigger moment which impacts development, or, if more severe, might even act as a 'jolt' which results in rethinking of self-identity as a leader (Aviolio \& Vogelgesang, 2011). Having the opportunity to reflect on what decisions led to the unsuccessful outcome and what better decisions might have been made provides learning which has the potential to improve leadership skills and create expertise which can be accessed in the future. Again, since males are more prone to risk-taking than females, this leadership development opportunity might be particularly suitable for young males.

\section{$\underline{\text { Effect of Context }}$}

In situations where risk taking is not to be encouraged, one action that can help to reduce this is to prevent groups of young people working together. Leading a group which consists only of peers is likely to promote greater risk taking. However, creating diverse action learning teams of mixed ages can reduce this (Hezlett, 2016). 
$\underline{\text { Temporal Discounting }}$

Adolescents and young adults are more influenced by immediate reward and less by delayed reward than adults. For this reason, rewards are more likely to be effective if they are linked directly and immediately to short-term outcomes than if they only occur when long-term goals are achieved. When leading projects, young employees should have regular meetings with mentors in which short term leadership goals can be set. Providing timely positive and constructive feedback on each goal provides the immediate reward to which young employees respond best and so helps in the development of a leadership identity. Ellis, Mendel and Nir (2006) evaluated feedback after successful outcomes and failures. They demonstrated that after successes, reflecting on things that went wrong is most effective while reflection of any kind is effective after failures.

\section{Prediction Errors}

Young adults are more sensitive to positive prediction errors than older adults. Positive prediction errors occur either when a reward is greater than expected or a punishment is less than expected. If successful outcomes are always linked to reward, the actual reward can be accurately predicted, therefore there is no longer a prediction error. It is therefore important to consider when and how much to reward success. Recent research suggests that there are two brain mechanisms for reward that compete against each other (Goto \& Grace, 2008). The first, which is linked to improvement in working memory, is looking for expected reward. If the expected reward occurs (no prediction error), we work harder to remember what we were doing at the time so that we can repeat this behaviour. However, a second neural network is activated by the absence of expected reward (negative prediction error). When this occurs, the best response is to try a new behaviour in order to seek new rewards. Thus intermittent rewards can create both negative (no reward when expected) and positive (reward when unexpected) errors. This keeps motivation high and activates new learning which leads to new skill acquisition. Mentors can be trained to provide intermittent praise for exceptional leadership behaviour.

Young adults are also less sensitive to negative prediction errors which occur when rewards are less than expected or when punishments are greater than expected. In order to prevent unwanted behaviours from repeating, it is therefore necessary to be particularly strict so that the negative prediction error is strong enough to be noticed and to prevent the behaviour in the future. Since leadership can be developed through observation of the actions of leaders (Yeager \& Callahan, 2016), it is important that unwanted leader and follower behaviours are consistently punished. If one member of a team is acting in a way that is not appropriate, being strict at the time will not only prevent the behaviour repeating for that member of staff, but this is also likely to create strong negative prediction errors for others who have 
witnessed the punishment. This models good leadership behaviour that can be imitated by young leaders.

\section{System 1 vs. System 2 Thinking}

When adults are new to an area in which they want to develop expertise, initially their performance is poor and depends on deliberate processing of immediately available information. Since expertise is not yet developed, decisions cannot be based on heuristics. Thus young employees have to rely on verbatim construction of each problem space. This type of deliberate decision making can be time consuming, and sometimes decisions have to be made more rapidly than this. One evolutionary solution to this lack of expertise would be to increase the rate at which experiences are obtained by increasing the sensitivity to reward and decreasing inhibition of risky decisions. The increased risk taking in adolescence makes more sense in this framework - it is a means of collecting a range of experiences as rapidly as possible resulting in an increasing ability to process by gist.

If this is the case, then, leadership can be developed by providing safe opportunities for individuals in their teens and early twenties to learn quickly through taking calculated risks. In addition, through mentorship, young people can be encouraged to think through decisions based on verbatim representations of the context of each decision (which they have the neural capacity to do well), and then helped to encode the gist of the decision. An additional way that this could be achieved would be by consciously accessing the ways in which expert leaders make their decisions and providing adolescents with some insight into this process through a leadership apprentice or training scheme (Haber \& Komives, 2009). Sharing of this nature, either in workplace or the training room, is likely to be highly rewarding for both the learner and the more experienced leader who will learn something about themselves in the process. Indeed, mentoring and coaching in leadership has been shown to increase the development of leadership skills by exposing potential leaders to new perspectives (Lewis \& Jacobs, 1992).

If time is not available to provide mentoring of this type, then helping adolescents and young adults to think through the relative rewards available in the short and long term, and encouraging them to precommit to the long term reward appears to improve the ability to resist immediate temptation (Crockett, Braams, Clark, Tobler, Robbins \& Kalenshcher, 2013). Alternatively, providing young people with a gist representation of the positive (benefits) and negative (risks) value of a decision can result in decreased risk taking (Reyna et al., 2011). Rather than treat adolescents as immature and lacking in self-control, we might benefit from considering them as beginners in the field of decision making and therefore help them to develop this skill by encouraging them to use the verbatim explanations that they are good at calculating, and providing them with the short-cuts that we use as experts. Additionally, we can benefit 
from their willingness to take risks by providing them with opportunities to participate in risky ventures in a safe environment. By changing our approach in these ways, we can help to accelerate leadership expertise while benefitting from the optimism of youth.

\section{Conclusions}

Organisations need to be able to train younger people to be good leaders whether they are introducing the concept of agile leadership, have an aging population of leaders who will need to be replaced in the near future, or are keen to capture the entrepreneurial talents of their younger employees. An understanding of the general challenges involved in training adolescents therefore has general applicability. This paper has outlined a number of strategies that could be used when developing the next generation of leaders, on the basis of an exploration of the difference in connectivity between adolescent and adult brains.

In particular, the relative maturity of structures which code reward and threat in comparison to the structures which regulate response to reward and threat were noted. The effects of this uneven maturation are that young people have a heightened response to reward and a reduced response to threat in comparison to adults. This results in greater risk taking especially in the presence of peers. In addition, young people are more responsive to immediate than delayed reward and are less able to accurately predict rewards than adults. Finally, young people lack the expertise which is required to create short cuts in thinking and so are more reliant on time-consuming cost-benefit analyses.

Creating the next generation of leaders requires young people to develop a leadership identity which includes both the motivation to lead and learning leadership behaviours. This will require rapid development of the parts of the brain which regulate reward and threat. Evidence suggests that experience with leadership positions and mentorship by successful leaders can accelerate this process. Thus, organisations can use this knowledge to develop training which will provide a pool of talented young people with the skills necessary both to lead within teams and to replace the generation of baby boomers as they retire.

\section{Future Directions}

In this paper, I have outlined a number of implications for leadership development that arise directly from an understanding of development of decision making in adolescents and young adults. This research was conducted both in the US (e.g. the research conducted by B.J. Casey and her team, and V.F. Reyna and her team both at Cornell University) in the UK (e.g. the research by S-J. Blakemore and her team at University College, London, K. Rubia and her team at King's College London, and A. Christakou and her team at 
University of Reading) and in Europe (L. van Leijenhorst and her team at Leiden University). The similarity of results across international laboratories suggests that these findings are appropriate for Western cultures. To date, however, there has been no similar research in Eastern cultures. This would provide a useful addition to this research area. Another useful addition to this field would be practitioner research that directly tested the predictions arising from this analysis by comparing leadership development in teams that implement these suggestions in comparison to those that do not.

Interestingly, some of the ways that have been suggested to develop leadership skills in young people made in this paper, have previously been used to compare individuals from the baby boomer generation with individuals from Generation Y (Hewlett, Sherbin \& Sumberg, 2009) or to discuss how to motivate Gen Y employees in particular (Nayar, 2013). Other commentaries have focussed on specific differences between generations, for instance, the prevalence of advice to Gen Y's that they should "follow their passion" with the implicit consequence that they should love their job from day one, therefore ignoring the fact that the hard work required to develop expertise is often a long and frustrating process (Newport, 2012). If this advice is not given to other generations, then this could produce group differences in motivation to work, and therefore in the kinds of leadership positions sought by Gen Y. The current analysis of the development of decision making suggests that, while differences related to generational culture or historical period will influence behaviour at work, commonalities also exist between generations of young people. Many of the attitudes to work and means to motivate young employees will have been effective in the past and will continue to be effective in the future. It is therefore important to differentiate factors that vary across cohorts and those that are common between cohorts. This analysis provides a basis for research designed to compare how best to motivate and develop leadership skills in young people in general against motivational techniques that are thought to be required for a particular new generation of employees. If some of the difficulties in motivating young people result from differences in the connections and maturation of their brain, it might not be necessary to re-invent ways to motivate each new generation. Instead, using our understanding of the neural underpinnings of behaviour in this group will allow us to design interventions that work for any generation.

\section{References}

Albert, D., Chein, J. \& Steinberg, L. (2013) Peer influences on adolescent decision making. Current Directions in Psychological Science, 22, 114-120.

Amodio, D.M. \& Frith, C.D. (2006) Meeting of minds: the medial frontal cortex and social cognition. Nature Reviews: Neuroscience, 7, 268-277.

Arnett, J.J. (1999) Adolescent storm and stress, reconsidered. American Psychologist, 54, 317-326. 
Aron, A.R., Robbins, T.W. \& Poldrack, R.A. (2004) Inhibition and the right inferior frontal cortex. Trends in Cognitive Sciences, 8, 170-177.

Aviolio, B.J. \& Vogelgesang Lester, G. (2011) Beginning matter in genuine leadership development. In: S.E. Murphy \& R.J. Reichard (eds) Early Development and Leadership: Building the Next Generation of Leaders. New York, NY: Psychology Press.

Blakemore, S-J. \& Robbins, T.W. (2012) Decision making in the adolescent brain. Nature Neuroscience, 15, 1184- 1191.

Campbell, A. \& Muncer, S. (2009) Can 'risky' impulsivity explain sex difference in aggression? Personality and Individual Differences, 47, 402-406.

Campion, M.A., Cheraskin, L. \& Stevens, M.J. (1994) Career-related antecedents and outcomes of job rotation. Academy of Management Journal, 37, 1518-1542.

Changing Global Demographics (2011) Retrieved August 8, 2016 from http://klminc.com/marketing/changing-global-demographics

Chikazoe, J., Konishi, S., Asari, T., Jimura, K. \& Miyashita, Y. (2007) Activation of right inferior frontal gyrus during response inhibition across response modalities. Journal of Cognitive Neuroscience, 19, 69-80.

Christakou, A. (2014) Present simple and continuous: emergence of self-regulation and contextual sophistication in adolescent decision-making. Neuropsychologia, 65, 302-312.

Christakou, A., Brammer, M., \& Rubia, K. (2011) Maturation of limbic corticostriatal activation and connectivity associated with developmental changes in temporal discounting. Neurolmage, 54, 13441354.

Christakou, A., Brammer, M. Giampietro, V. \& Rubia, K. (2009) Right ventromedial and dorsolateral prefrontal cortices mediate adaptive decisions under ambiguity by integrating choice utility and outcome evaluation. Journal of Neuroscience, 29, 11020-11028.

Cohen, J.R., Asarnow, R.F., Sabb, F.W., Bilder, R.M., Bookheimer, S.Y., Knowlton, B.J. \& Poldracik, R.A. (2010) A unique adolescent response to reward prediction errors. Nature Neuroscience, 13, 1-3.

Cosmides, L. \& Tooby, J. (1996) Are humans good intuitive statisticians after all? Rethinking some conclusions from the literature on judgement under uncertainty. Cognition, 58, 1-73.

Crockett, M.J., Braams, B.R., Clark, L., Tobler, P.N., Robbins, T.W. \& Kalenshcher, T. (2013) Resetricting temptations: neural mechanisms of precommitment. Neuron, 79, 391-401.

Daimler, M. (2016) Why leadership development has to happen on the job, Harvard Business Review, March 16, 2016.

Day, D., Fleenor, J., Atwater, L., Sturm, R. \& McKee, R. (2014) Advances in leader and leadership development: a review of 25 years of research and theory. The Leadership Quarterly, 25, 63-82.

Dreyfuss, M., Caudle, K., Drysdale, A., Johnston, N., Cohen, A., Somerville, L., Galvan, A., Tottenham, N., Hare, T. \& Casey, B.J. (2014) Teens impulsively react rather than retreat from threat. Developmental Neuroscience, 36, 220-227.

Ellis, S., Mendel, R. \& Nir, M. (2006) Learning from successful and failed experience: The moderating role of kind of after-event review. Journal of Applied Psychology, 91, 669-680.

Ernst, M., Pine, D.S. \& Hardin, M. (2006) Triadic model of the neurobiology of motivated behaviours in adolescence. Psychological Medicine, 36, 299-312.

Ernst, M. \& Spear, L.P. (2009) Reward Systems. In, de Haan, M., Gunnar, M.R. (eds) Handbook of Developmental Social Neuroscience, New York: Guilford Press. 
Evans, J.S.B.T. (2003) In two minds: dual-process accounts of reasoning. Trends in Cognitive Sciences, 7, 454-459.

Galvan, A., Hare, T.A., Parra, C.E., Penn, J., Voss, H., Glover, G. \& Casey, B.J. (2006) Earlier development of the accumbens relative to orbitofrontal cortex might underlie risk-taking behaviour in adolescents. Journal of Neuroscience, 26, 6885-6892.

Goto, Y. \& Grace, A. (2008) Limbic and cortical information processing in the nucleus accumbens. Trends in Neuroscience, 31, 552-558.

Haber, P. \& Komives, S.R. (2009) Predicting the individual values of the social change model of leadership development: The role of college students' leadership and involvement experiences. Journal of Leadership Education, 7, 133-166.

Hewlett, S.A., Sherbin, L. \& Sumberg, K. (2009) How Gen Y \& Boomers will reshape your agenda. Harvard Business Review, July-August 2009.

Hezlett, S.A. 92016) Enhancing experience-driven leadership development. Advances in Developing Human Resources, 18, 369-389.

Jones, R.M., Somerville, L.H., Li, J., Ruberry, E.J., Powers, A., Mehta, N. Dyke, J. \& Casey, B.J. (2014) Adolescent-specific patterns of behaviour and neural activity during social reinforcement learning. Cognitive, Affective and Behavioral Neuroscience, 14, 683-697.

Kahneman, D. (2011) Thinking, Fast and Slow. London, UK: Penguin Press.

Kraiger, K., Ford, J.K. \& Salas, E. (1993) Application of cognitive, skill-based and affective theories of learning outcomes to new methods of training evaluation. Journal of Applied Psychology, 78, 311328.

Leonard, H.S. \& Marquardt, M.J. (2010) The evidence for the effectiveness of action learning. Action Learning: Research and Practice, 7, 121-136.

Lewis, P.M. and Jacobs, T.O. (1992) Individual differences in strategic leadership capacity: a constructive/development view, in Phillips, R.L. and Hunt, J.G. (Eds), Strategic Leadership: A Multiorganizational Perspective, Westport, CT:Quorum Books, 121-137.

Loughran, T., Paternoster, R. \& Weiss, D. (2012) Hyperbolic time discounting, offender time preferences and deterrence. Journal of Quantitative Criminology, 28, 607.

Luna, B., Padmanabhan, A. \& O'Hearn, K. (2010) What has fMRI told us about the development of cognitive control through adolescence? Brain and Cognition, 72, 101-112.

Marsh, R., Zhu, H., Schultz, R.T., Quackenbush, G., Royal, J., Skudlarski, P. \& Peterson, B.S. (2006) A developmental study of self-regulatory control. Human Brain Mapping, 27, 848-863.

McCall, M.W. Jr., Lombardo, M.M. \& Morrison, A.M. (1988) The Lessons of Experience: How Successful Executives Develop on the Job. Lexington, MA: Lexington Press.

McCauley, C.D. \& Van Velsor, E. (2004) The Center for Creative Leadership Development, San Francisco, CA:Jossey-Bass.

Miller, E.J. (1998), "The leader with the vision: is time running out?", in Klein, E.B., Gabelnick, F. and Herr, P. (Eds), The Psychodynamics of Leadership, Madison, CT: Psychosocial Press, 3-25.

Nayar, V. (2013) Handing the keys to Gen Y. Harvard Business Review, May 2013.

Newport, C. (2012) Solving Gen Y's passion problem. Harvard Business Review, September 18, 2012.

Pearce, C.L. (2004) The future of leadership: combining vertical and shared leadership to transform knowledge work, Academy of Management Executive, 18, 47-57. 
Rachlin, H. \& Green, L. (1972) Commitment, choice and self-control. Journal of the Experimental Analysis of Behavior, 17, 15-22.

Reyna,V.F. (2012) A new intuitionism: Meaning, memory and development in fuzzy-trace theory. Judgement and Decision Making, 7, 332-359.

Reyna, V.F. \& Brainerd, C.J. (1991) Fuzzy-trace theory and faming effects in choice: Gist extraction, truncation, and conversion. Journal of Behavioural Decision Making, 4, 249-262.

Reyna, V.F., Chick, C.F., Corbin, J.C. \& Hsia, A.N. (2013) Developmental reversals in risky decision making: Intelligence agents show larger decision biases than college students. Psychological Science, 25, 7684.

Reyna, V.F., Estrada, S.M., DeMarinis, J.A., Myers, R.M., Stanisz, J.M. \& Mills, B.A. (2011) Neurobiological and memory models of risky decision making in adolescents versus young adults. Journal of Experimental Psychology. Learning, Memory, and Cognition, 37, 1125-1142.

Rubia, K., Lim, L., Ecker, C., Halari, R., Giampietro, V., Simmons, A., Brammer, M. \& Smith, A. (2013) Effects of age and gender on neural networks of motor response inhibition: From adolescence to midadulthood. Neurolmage, 83, 690-703.

Rubia, K., Hyde, Z., Halari, R., Giampietro, V. \& Smith, A. (2010) Effects of age and sex on developmental neural networks of visual-spatial attention allocation. Neurolmage, 51, 817-827.

Rubia, K., Smith, A., Taylor, E. \& Brammer, M. (2007) Linear age-correlated functional development of right inferior fronto-striato-cerebellar networks during response inhibition and anterior cingulate during error-related processes. Human Brain Mapping, 28, 1163-1177.

Schneider, M. (2002) A stakeholder model of organizational leadership. Organization Science, 13, 209.

Sebastian, C., Burnett, S. \& Blakemore, S-J. (2008) Develop0ment of the self-concept during adolescence. Trends in Cognitive Sciences, 12, 441-446.

Silva, K., Chein, J. \& Steinberg, L. (2016) Adolescents in peer groups make more prudent decisions when a slightly older adult is present. Psychological Science, doi:10.1177/0956797615620379

Somerville, L.H., Hare, T. \& Casey, B.J. (2011) Frontostriatal maturation predicts cognitive control failure to appetitive cues in adolescents. Journal of Cognitive Neuroscience, 23, 2123-2134.

Steinberg, L. (2010) A dual systems model of adolescent risk-taking. Developmental Psychobiology, 52, 216-224.

Steinberg, L. (2008) A social neuroscience perspective on adolescent risk taking. Developmental Review, $28,78-106$.

Steinberg, L. (2007) Risk taking in adolescence: New perspectives from brain and behavioral science. Current Directions in Psychological Science, 16, 55-50.

Tversky, A. \& Kahneman, D. (1974) Judgement under uncertainty: Heuristics and biases. Science, 185, 1124-1131.

Tversky, A. \& Kahneman, D. (1986) Rational choice and the framing of decisions. Journal of Business, 59, 251-278.

van Leijenhorst, L., Moor, B.G., Op de Macks, Z.A., Rombouts, S.A.R.B., Westenberg, P.A. \& Crone, E.A. (2010) Adolescent risky decision-making: neurocognitive development of reward and control regions. Neurolmage, 51, 345-355.

Viner, R.M., Ozer, E.M., Denny, S., Marmot, M., Resnick, M., Fatsui, A. \& Currie, C. (2012) Adolescence and the social determinants of health. Lancet, 379, 1641-1652. 
Weinstein, S.M., Mermelstein, R.J., Hankin, B.L., Hedeker, D. \& Flay, B.R. (2007) Longitudinal patterns of daily affect and global mood during adolescence. Journal of Research in Adolescence, 17, 587-600.

Yeager, K.L. \& Callahan, J.L. (2016) Learning to lead: Foundations of emerging leader identity development. Advances in Developing Human Resources, 18, 286-300. 
Table 1: Implications of each area of brain development for guiding leadership development in adolescents and young adults with suggested actions

\begin{tabular}{|l|l|l|}
\hline Neural Development & Implication & Leadership Development \\
\hline Inhibition & $\begin{array}{l}\text { Less able to inhibit behaviours } \\
\text { Males less able to inhibit than females }\end{array}$ & $\begin{array}{l}\text { Develop inhibition through experiences } \\
\text { in situations where self-regulation is } \\
\text { required in order to lead by example }\end{array}$ \\
\hline Reward & Increased sensitivity to reward & $\begin{array}{l}\text { Provide a mentor who can give positive } \\
\text { and constructive feedback on } \\
\text { performance after appropriately } \\
\text { challenging leadership opportunities }\end{array}$ \\
\hline Risk & $\begin{array}{l}\text { Decreased sensitivity to risk especially } \\
\text { in males }\end{array}$ & $\begin{array}{l}\text { Offer opportunities to lead on higher } \\
\text { risk projects with low cost of failure in } \\
\text { order to sensitise to the effects of } \\
\text { taking unnecessary risks }\end{array}$ \\
\hline Effect of Context & $\begin{array}{l}\text { Greater risk taking with peers but } \\
\text { reduced when older person present }\end{array}$ & $\begin{array}{l}\text { Allow individuals to lead on projects } \\
\text { including mixed ages groups to } \\
\text { discourage unwanted risk taking }\end{array}$ \\
\hline Temporal Discounting & Less sensitive to long term reward & Reward little and often \\
\hline Prediction Errors & Sensitive to positive prediction errors & $\begin{array}{l}\text { Train mentors to make rewards } \\
\text { intermittent to provide unexpected } \\
\text { positive prediction errors }\end{array}$ \\
& Less sensitive to negative prediction \\
errors & $\begin{array}{l}\text { behaviour has not met expectation to } \\
\text { create strong negative prediction errors }\end{array}$ \\
\hline System 1 vs System 2 & $\begin{array}{l}\text { More dependence on system 2 since } \\
\text { expertise has not yet been acquired }\end{array}$ & $\begin{array}{l}\text { Use leadership by example to teach the } \\
\text { shortcuts used by experienced leaders. } \\
\text { Use coaching to reflect on leadership } \\
\text { experiences using system 2. }\end{array}$ \\
\hline
\end{tabular}


Figure 1: The triadic brain: A model of the system used in decision making (adapted from: Ernst, Pine \& Hardin, 2006). 